\title{
Relocation of large intermediate-depth earthquakes in the Vrancea region, Romania, since 1934 and a seismic gap
}

\author{
Nobuo Hurukawa ${ }^{1}$, Mihaela Popa ${ }^{2}$, and Mircea Radulian ${ }^{2}$ \\ ${ }^{1}$ International Institute of Seismology and Earthquake Engineering (IISEE), Building Research Institute, \\ Tsukuba, Ibaraki 305-0802, Japan \\ ${ }^{2}$ National Institute for Earth Physics (NIEP), Bucharest, Romania
}

(Received July 6, 2007; Revised December 11, 2007; Accepted January 8, 2008; Online published July 4, 2008)

\begin{abstract}
We relocated $M 6$ or larger intermediate-depth earthquakes in Vrancea, Romania that have occurred since 1934. To determine their absolute hypocenters accurately, we combined them with recent (from January 1996 to November 2003) smaller earthquakes recorded by the Romanian local network and then relocated all of them simultaneously using a modified joint hypocenter determination method. Using the data on recent small earthquakes we first obtained an estimate of the dimensions of the active seismic region of intermediate-depth earthquakes: length, $85 \mathrm{~km}$; along a NE-SW direction; width, $20 \mathrm{~km}$; depth 60-160 km. We then determined that the 1940 (M 7.7), 1977 (M 7.5) and 1990 (M 6.9) major earthquakes were located near the NE edge of the seismic region, while the 1986 (M 7.2) was located inside the seismic region. The focal depths of the 1940, 1977, 1986 and 1990 major earthquakes were calculated to be 124, 98, 135 and $84 \mathrm{~km}$, respectively and their source areas to range from 60 to $140 \mathrm{~km}$ in depth. The only unbroken area is at a depth of $140-160 \mathrm{~km}$, which we current consider to be a seismic gap. Based on the regularity of past large earthquakes, we propose that the next $M 7$ intermediate-depth earthquake can be expected to occur in Vrancea at a depth interval of 140-160 km sometime early in this century.
\end{abstract}

Key words: Relocation, joint hypocenter determination, intermediate-depth earthquake, Vrancea, Romania.

\section{Introduction}

Isolated intermediate-depth earthquakes occur regularly in the SE corner of the Carpathian arc in central Romania (Fig. 1; see Frohlich, 2006). The depths of these earthquakes range from 60 to $160 \mathrm{~km}$, and their epicenters are concentrated in an area of $20 \times 85 \mathrm{~km}$ in the Vrancea region. Based on the regularity of past large earthquakes, the predominant focal mechanism is of a thrust type with a NWSE compressional axis. Since no plate boundary is present, a paleo-subduction is assumed in the zone (e.g. Fuchs et al., 1979; Wortel and Spakman, 2000; Sperner et al., 2004). According to the Romanian earthquake catalog ROMPLUS (Oncescu et al., 1999), five earthquakes of magnitude (M) 7 or greater have occurred every 100 -year period over the last 500 years. Although these are intermediate-depth earthquakes, the larger events have caused severe damage in the city of Bucharest, located about $150 \mathrm{~km}$ from the epicenter, as well as in other cities in Romania and neighboring countries. For example, in 1977 a moment magnitude $\left(M_{\mathrm{w}}\right) 7.5$ earthquake caused 1,581 deaths.

Various investigations have assessed the likelihood of future earthquake activity with the aim of reducing the risk of disasters as a consequence of such earthquakes (Purcaru, 1974, 1979; Enescu et al., 1974; Radulian and Trifu, 1991; Enescu and Enescu, 1996, 1999; Imoto and Hurukawa,

Copyright (c) The Society of Geomagnetism and Earth, Planetary and Space Sciences (SGEPSS); The Seismological Society of Japan; The Volcanological Society of Japan; The Geodetic Society of Japan; The Japanese Society for Planetary Sciences; TERRAPUB
2006). Using a stress-release model based on data for the last 500 years, Imoto and Hurukawa (2006) concluded that there was a $30 \%$ probability that a $M \geq 7.0$ earthquake will occur during a 5-year period starting in 2005.

In general, long-term earthquake predictions are based on the regularity of earthquake occurrences and a seismic gap model (e.g. Fedotov, 1965; Sykes, 1971). Such an approach is particularly relevant in subduction zones, where a distinct geophysical background (plate tectonics) and short recurrence time allow researchers to make practical use of the prediction (e.g., Headquarters for Earthquake Research Promotion, 2007). Since an $M 7$ intermediate-depth earthquake typically occurs in the Vrancea region about every 20-30 years and the last major earthquake occurred in 1986 $\left(M_{\mathrm{w}} 7.2\right)$, we can expect the next large earthquake to occur in the near future.

Purcaru (1974) analyzed the earthquake catalog since 1100 A.D. up to the present and found some regularities in the seismic activity of Vrancea intermediate-depth earthquakes. He was able to show three active (seismic) timebands (years 0-10, 30-40 and 70-90 for each century) that alternated with quiet intervals and "quasicycles" of about 100 years. The author concluded:

"Thus, following an algorithm of extrapolation, the final results appear to indicate the occurrence of a shock with $M=6 \frac{3}{4}-7$ in $1980 \pm 13$ years. Later earthquakes were predicted in 2005 , in 2030-40 ( $\left.M=6 \frac{3}{4}-7\right)$ and one with nearly maximum magnitude $\left(M=7 \frac{1}{2}-7 \frac{3}{4}\right)$ in 2070- 


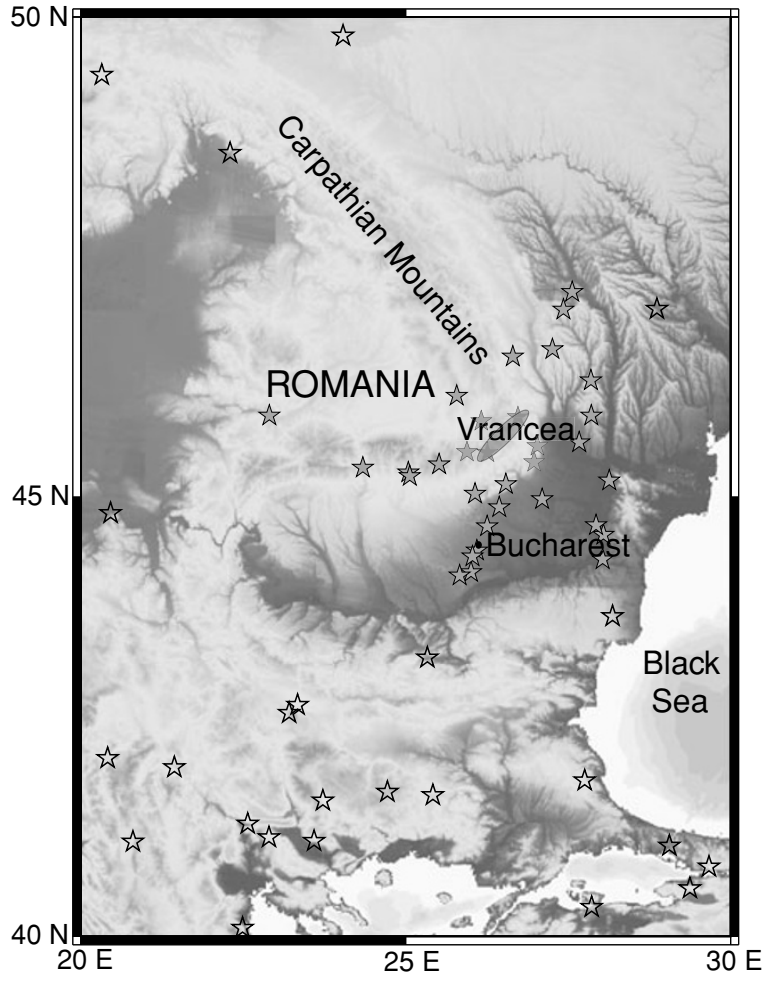

Fig. 1. Earthquakes of the Vrancea region in Romania. An ellipsoid indicates the epicentral area of Vrancea intermediate-depth earthquakes defined in this study. Stars indicate nearby stations among the 140 stations used in relocation. Solid and open stars indicate NIEP (Romania) and non-NIEP stations, respectively.

\section{$80 ”$.}

Enescu et al. (1974) published a statistical prediction based on their study of the earthquake catalog since 1471 A.D.: there would be high seismic activity during the period 1978-1990 with a main peak of seismic intensity $I_{\mathrm{o}}=8-9$ on the MSK-64 scale. In reality, an $M_{\mathrm{w}} 7.5$ earthquake occurred in 1977. According to Purcaru (1979), the magnitude of this earthquake was $7.1\left(M_{\mathrm{B}} 7.1, M_{\mathrm{s}} 7.1\right)$, thus confirming the success of his prediction. Although the $1986 M_{\mathrm{w}} 7.2$ and $1990 M_{\mathrm{w}} 6.9$ earthquakes were not predicted, the authors did predict a large earthquake around 2005, which corresponds to the next active time-band (years 0-10). However, these studies were not based on the seismic gap theory nor on precise hypocenters, especially focal depths, and to establish a reliable prediction, it is also important to determine accurate hypocenters for older events and to evaluate the location of the next large earthquake. The goal of the research reported here was to relocate old earthquakes accurately and to evaluate the location of the next large earthquake in the Vrancea region.

\section{Relocation Method}

We report here the relocation of the hypocenters of past large earthquakes using the Modified Joint Hypocenter Determination (MJHD) method (Hurukawa and Imoto, 1992; Hurukawa, 1995) and our analysis of the relationship between past large earthquakes and recent seismicity. Due to the lateral heterogeneity of the Earth, the assumption of the horizontally homogeneous velocity model, which is nor- mally used in hypocenter determination, is inadequate to obtain the precise location of earthquakes. We therefore define a station correction that accounts for the lateral heterogeneity of the Earth. The Joint Hypocenter Determination (JHD) method is a generalization of the single-event method that includes station corrections for travel times as additional parameters to be determined from a group of earthquakes (Douglas, 1967; Freedman, 1967). The hypocenters of many earthquakes and station corrections can then be calculated simultaneously. We relocate earthquakes using the MJHD method to determine their relative location accurately and stably. Compared with the conventional JHD method, the MJHD method has three additional constraints:

$$
\begin{aligned}
& \sum_{i=1}^{n} S_{i} * d D_{i}=0, \quad \sum_{i=1}^{n} S_{i} * \cos \theta_{i}=0, \\
& \sum_{i=1}^{n} S_{i} * \sin \theta_{i}=0
\end{aligned}
$$

where $d D_{i}=D_{i}-\operatorname{AVE}(D)$, and $S_{i}$ is the station correction at the $i$-th station, $D_{i}$ is the distance of the $i$-th station from the center of the area, $\operatorname{AVE}(D)$ is the average of distances, $\theta_{i}$ is the azimuth of the $i$-th station relative to the center of the area, and $n$ is the number of stations. These conditions imply that a station correction is independent of both the distance and the azimuth from the center of the studied region to the station. Although these conditions affect the absolute hypocenters, they stabilize the JHD method.

Since our objective is to obtain not only the relative location but also the absolute location of earthquakes, we introduce additional coefficients, $a_{1}, a_{2}$, and $a_{3}$, to improve absolute location:

$$
\begin{aligned}
& \sum_{i=1}^{n}\left(S_{i}-a_{1} * D_{i}^{\prime}\right) * d D_{i}=0, \\
& \sum_{i=1}^{n}\left(S_{i}-a_{2} * \cos \theta_{i}\right) * \cos \theta_{i}=0, \\
& \sum_{i=1}^{n}\left(S_{i}-a_{3} * \sin \theta_{i}\right) * \sin \theta_{i}=0
\end{aligned}
$$

where $D_{i}^{\prime}=D_{i} / \operatorname{AVE}(D)-1$. When $a_{1}, a_{2}$ and $a_{3}$ are all zero, Eq. (2) becomes Eq. (1). If we use these additional parameters, we can arbitrarily shift the location of the earthquakes: a change in $a_{1}, a_{2}$ and $a_{3}$ results in an adjustment of our location relative to the reference location of earthquakes that are believed to be very reliable. As such, we find the best values in which both locations coincide with each other. This implies that we can obtain absolute locations for older earthquakes accurately, if the reference location is absolutely reliable. Note that we use the iaspei91 travel-time table in the calculation of travel times.

\section{Data and Results}

The National Institute for Earth Physics (NIEP) in Bucharest operates a dense local network (Fig. 1) in cooperation with the University of Karlsruhe (Germany) and has provided high-accuracy hypocenter locations for Vrancea 
Table 1. List of relocated hypocenters of earthquakes with $M \geq 6.0$.

\begin{tabular}{|c|c|c|c|c|c|}
\hline Date & Time & Longitude $\left({ }^{\circ} \mathrm{E}\right)$ & Latitude $\left({ }^{\circ} \mathrm{N}\right)$ & Depth $(\mathrm{km})$ & Magnitude \\
\hline $1934 / 03 / 29$ & $20: 0649.09 \pm 0.27$ & $26.725 \pm 0.023$ & $45.656 \pm 0.028$ & $105.6 \pm 4.2$ & $6.2^{1)}$ \\
\hline $1940 / 10 / 22$ & $06: 3702.16 \pm 0.31$ & $26.699 \pm 0.033$ & $45.611 \pm 0.029$ & $126.4 \pm 3.8$ & $6.5^{1)}$ \\
\hline $1940 / 11 / 10$ & $01: 3907.40 \pm 0.24$ & $26.932 \pm 0.023$ & $45.753 \pm 0.026$ & $123.8 \pm 3.0$ & $7.7^{2)}$ \\
\hline $1945 / 09 / 07$ & $15: 4827.31 \pm 0.28$ & $26.738 \pm 0.030$ & $45.732 \pm 0.027$ & $88.8 \pm 3.8$ & $6.5^{1)}$ \\
\hline $1945 / 12 / 09$ & $06: 0846.03 \pm 0.35$ & $26.935 \pm 0.039$ & $45.532 \pm 0.031$ & $89.4 \pm 4.3$ & $6.0^{1)}$ \\
\hline $1977 / 03 / 04$ & $19: 2154.06 \pm 0.14$ & $26.969 \pm 0.019$ & $45.851 \pm 0.014$ & $98.1 \pm 2.0$ & $7.5^{3)}$ \\
\hline $1986 / 08 / 30$ & $21: 2836.26 \pm 0.07$ & $26.587 \pm 0.011$ & $45.554 \pm 0.008$ & $135.0 \pm 1.0$ & $7.2^{3)}$ \\
\hline $1990 / 05 / 30$ & $10: 4008.05 \pm 0.08$ & $26.977 \pm 0.013$ & $45.890 \pm 0.009$ & $83.8 \pm 1.3$ & $6.9^{3)}$ \\
\hline $1990 / 05 / 31$ & $00: 1744.06 \pm 0.12$ & $26.997 \pm 0.019$ & $45.883 \pm 0.013$ & $81.8 \pm 1.9$ & $6.3^{3)}$ \\
\hline
\end{tabular}

${ }^{1)} M_{\mathrm{S}}$ by International Seismological Summary (ISS), ${ }^{2)} M_{\mathrm{w}}$ by Oncescu et al. (1999) (Note that $M_{\mathrm{S}}$ by ISS is 7.4.), ${ }^{3)} M_{\mathrm{w}}$ by Harvard University (Dziwonski et al., 1981, and later updates).

earthquakes since continuous digital acquisition of the seismological data began in 1991. Since this network has a number of three-component stations, when $S$-wave arrivals are available both $P$ - and $S$-wave arrivals are used for locating earthquakes to obtain accurate hypocenters. However, earlier, in particular prior to the 1980's, the information was poor and scarce. For example, the $1940 M_{\mathrm{w}} 7.7$ earthquake was recorded and reported at 150 stations worldwide, but in Romania it was only recorded at the Bucharest station. Therefore, we use NIEP locations for recent events for the reference locations because these locations were determined by the dense local network and are, therefore, the most reliable.

We use two datasets to relocate older earthquakes with high accuracy: (1) past larger earthquakes from 1934 to 1990 and (2) recent smaller earthquakes from January 1996 to November 2003 . In both cases, only $P$-wave first arrivals are used in relocation because the reading accuracy of $S$ wave arrival times is worse than that of $P$-wave arrivals. Since the stations used and the reading accuracies in the two datasets are quite different from each other, we first relocate them separately, and only later combine the two datasets. With this approach, we are able to easily remove bad readings from each dataset and, therefore, improve the accuracies of the hypocenters.

The first dataset consists of all $M \geq 6.0$ earthquakes from 1934 to 1990 (Table 1) and the aftershocks of the four largest earthquakes mentioned below. Note that not a single $M \geq 6.0$ earthquake has occurred after 1991, while four earthquakes with $M \geq 6.9$ occurred in the period between 1934 and 1990. To obtain the respective aftershock areas and to increase the numbers of readings at stations that recorded these larger earthquakes, we also locate their aftershocks. We considered the following aftershock activity intervals for relocation: 10-23 November 1940, 4 March30 April 1977, 30-31 August 1986 and 30-31 May 1990. We used $P$-wave arrival times reported by the International Seismological Summary (ISS) before 1963 and those reported by the International Seismological Centre (ISC) after 1964. There are a number of readings for which travel-time residuals are close to multiple of $60 \mathrm{~s}$ for earthquakes in the 1930s and 1940s. Since it is clear that this was caused by a misreading of the minute marks of the arrival times, we have corrected these. The following criteria determined the selection of events and stations: (1) a minimum of eight stations must have observed each event (MSTN): (2) a minimum of five events had to be observed at each station (MEVN): (3) the readings for which travel-time residuals (O-C) were $\geq 2.5 \mathrm{~s}$ were excluded. Applying these criteria, we identified 122 stations worldwide that could be used for locating 47 earthquakes.

The second dataset consists of all earthquakes that occurred from January 1996 to November 2003; these were located by the NIEP. We selected earthquakes that had occurred in the rectangle: $44.8^{\circ} \mathrm{N}-46.4^{\circ} \mathrm{N}$ latitude, $25.5^{\circ} \mathrm{E}-$ $27.5^{\circ} \mathrm{E}$ longitude for all depth ranges. Although a total of 1996 earthquakes were located, events and stations were selected on the following criteria: (1) MSTN is six; (2) MEVN is 30; (3) the readings for which $\mathrm{O}-\mathrm{C} \geq 1.0 \mathrm{~s}$ were excluded. When we relocated these earthquakes assuming $a_{i}=0(i=1,3)$ in Eq. (2), the relocated hypocenters of earthquakes significantly differed from the NIEP locations. Therefore, changing $a_{i}(i=1,3)$, we searched for the best locations that coincide, on average, with NIEP catalog locations. The best locations were obtained when $a_{1}=-0.3$, $a_{2}=0.0$, and $a_{3}=0.0$ in Eq. (2). Ultimately, we located 502 earthquakes using 26 stations operated by the NIEP. We refer to these locations as Location 2.

Combining the two datasets, after removing the bad readings, we jointly relocated all earthquakes in the two datasets. Because older events were recorded at fewer stations than recent ones, we changed the selection criteria to the following: (1) MSTN is six; (2) MEVN is five; (3) the readings for which $\mathrm{O}-\mathrm{C} \geq 3.0 \mathrm{~s}$ were excluded. When we relocated these earthquakes assuming $a_{i}=0(i=1,3)$ in Eq. (2), the relocated hypocenters of earthquakes that occurred between January 1996 and November 2003 significantly differ from NIEP locations. Therefore, changing $a_{i}$ ( $i=1,3)$, we searched for the best locations that coincide, on average, with Location 2. Both locations coincide each other when $a_{1}=0.3, a_{2}=-0.7$ and $a_{3}=1.1$ in Eq. (2) (Fig. 2). The scattering became small in this location, and the average differences are $0.06^{\circ}$ latitude, $0.06^{\circ}$ longitude and $7 \mathrm{~km}$ depth. In this manner, we were able to relocate all earthquakes, including older ones, of which relative locations to recent earthquakes located by the dense local network are very accurate. We found 549 earthquakes using the 140 stations shown in Figs. 1 and 3. Hypocenters of earthquakes with $M \geq 6.0$ are listed in Table 1 . In this table, standard errors of hypocenters are also shown, 

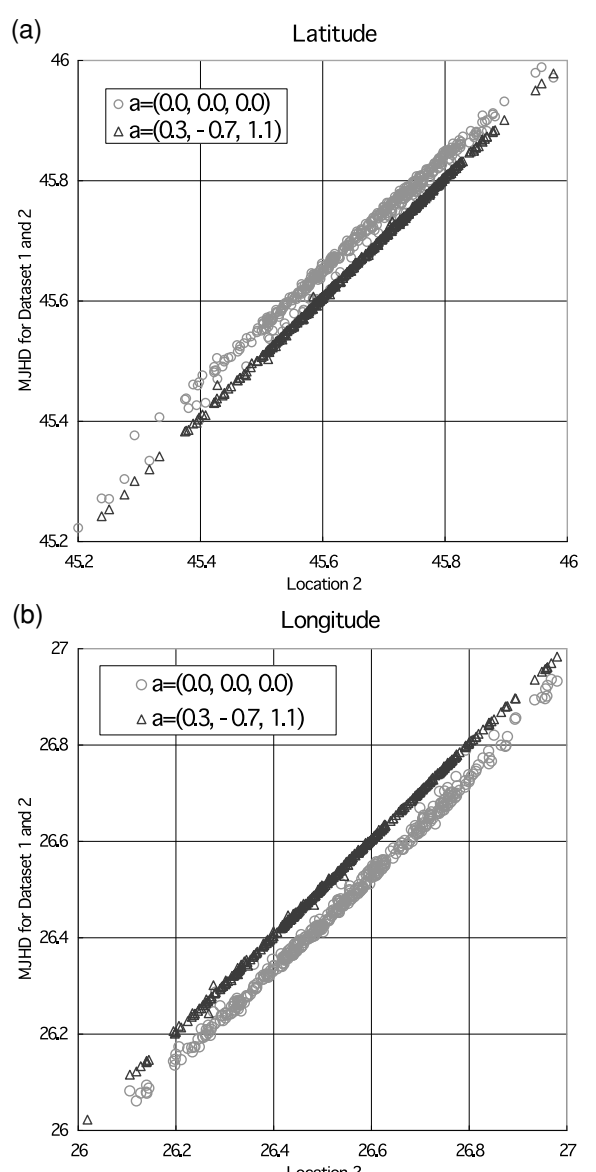

(c) Depth, $\mathrm{km} \quad$ Location 2

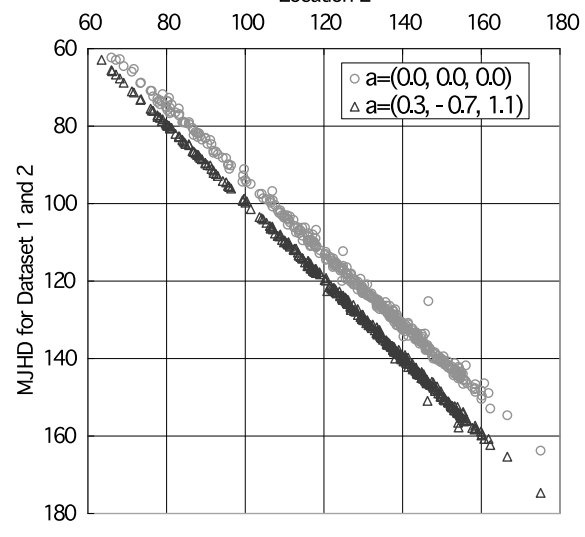

Fig. 2. Comparison of (a) latitude, (b) longitude and (c) focal depth of relocated hypocenters of earthquakes during the period from January 1996 to November 2003 for two parameter sets of $a_{i}(i=1,3)$.

which were calculated by multiplying diagonal elements of the inverse matrix of observational equation by travel-time residuals. Since the number of stations used for relocation is large, calculated standard errors of hypocenters are very small. The results are explained in more detail in the following section.

\section{Relocated Hypocenters}

Relocated hypocenters are shown in Figs. 4 and 5. Figure 4(b) shows earthquakes from January 1996 to November 2003 which, following relocation, are concentrated in

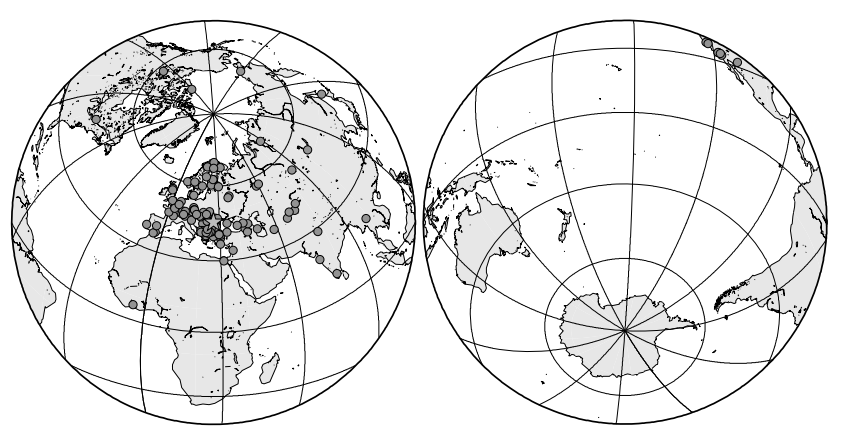

Fig. 3. Stations used in this study. Solid circles indicate the 140 stations used for relocation. Nearby stations are shown in Fig. 1. The epicentral area of Vrancea earthquakes is shown by a star.

a smaller region than the original cataloged hypocenters shown in Fig. 4(a); in addition, intermediate-depth earthquakes are clearly separated from crustal earthquakes. We were also able to define the three-dimensional seismic region where intermediate-depth earthquakes are generated. Figure 4(b) also shows the seismic region by solid contours. The criteria used to draw the boundary of the seismic region are: (1) ellipse in the horizontal plane; (2) smooth in the vertical cross sections; (3) concentration of earthquakes. Based on these criteria, some earthquakes occurred outside of the seismic region.

The epicentral area is $85 \mathrm{~km}$ long in a NE-SW direction and $20 \mathrm{~km}$ wide. It is nearly vertical in the depth range from 60 to $120 \mathrm{~km}$; at greater depths, it dips about 70-80 degrees northwestward. The NE-SW horizontal extension increases in depth down to $110 \mathrm{~km}$ and reaches a maximum of $70 \mathrm{~km}$ at a depth of $110-135 \mathrm{~km}$, following which it decreases rapidly down to $160 \mathrm{~km}$. The average thickness of the region is $15 \mathrm{~km}$.

These results agree with those of Oncescu and Bonjer (1997) who relocated the best recorded microearthquakes in the Vrancea region during the period 1982-1989 with the JHD method. However, our calculated horizontal length of the seismic region is about $20 \mathrm{~km}$ longer than that by calculated by Oncescu and Bonjer (1997). This comparison suggests an expansion of the seismic region.

The 1940 (M 7.7) earthquake was located at the NE edge of the seismic region, and its focal depth is $124 \pm 3 \mathrm{~km}$ (Table 1; Figs. 5(a), 6). The 1977 (M 7.5) and 1990 (M 6.9) earthquakes were located about $5-10 \mathrm{~km}$ NE of the seismic region, and their focal depths are $98 \pm 2$ and $84 \pm 1 \mathrm{~km}$, respectively (Table 1; Figs. 5(b), 5(d), 6).

The focal depth of the 1977 (M 7.5) earthquake in this study is $12 \mathrm{~km}$ deeper than the catalog depth of $86 \mathrm{~km}$. Fuchs et al. (1979) analyzed aftershocks of the 1977 earthquake using fixed and supplementary mobile seismic stations and found that aftershocks occurred at depths of 70$130 \mathrm{~km}$. According to their figures many of aftershocks occurred between a depth of 80 and $110 \mathrm{~km}$, so that the presumed aftershock area in Fig. 6(b) coincides well with their study.

In contrast, the 1986 (M 7.2) earthquake was located inside the seismic region and its focal depth is $135 \pm 1 \mathrm{~km}$ (Table 1; Figs. 5(c), 6), which is in good agreement with 
(a)
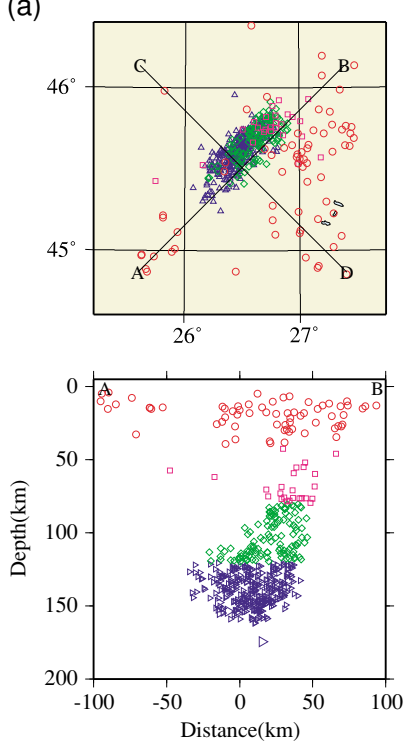
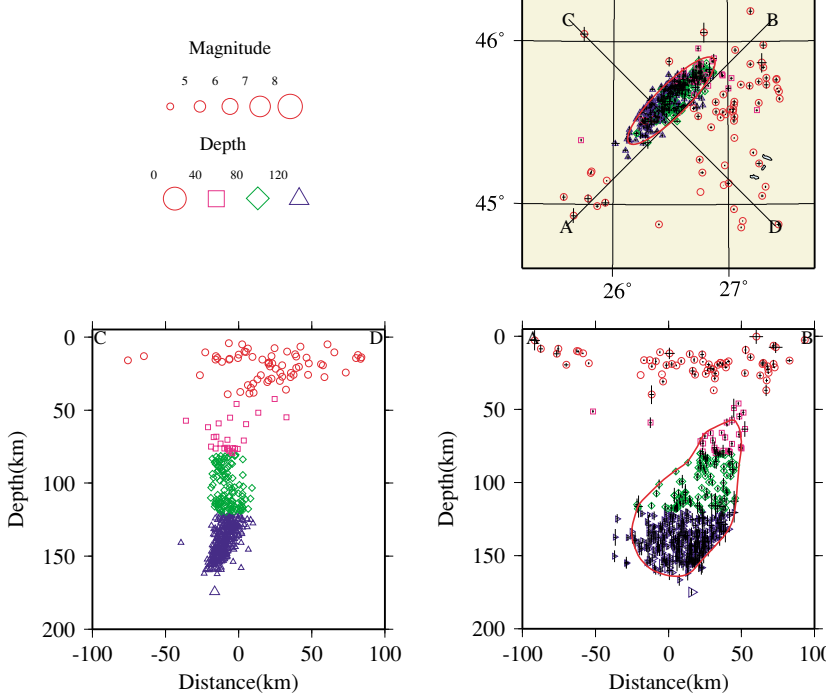

(b)

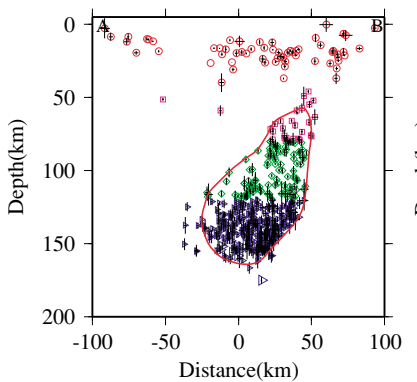

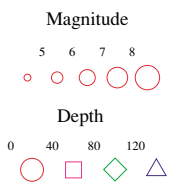

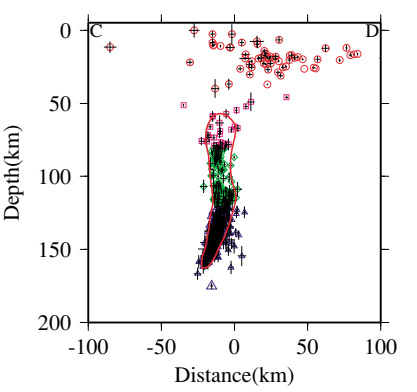

Fig. 4. Hypocenters of earthquakes occurred from January 1996 to November 2003. Epicentral distribution and two vertical cross sections along the A-B and C-D lines are shown. Different symbols represent different focal depths of earthquakes. Sizes of symbols differ according to magnitudes of earthquakes. (a) Catalog hypocenters, (b) relocated hypocenters (Location 2). Only earthquakes of which standard errors of focal depths are less than $10 \mathrm{~km}$ are plotted. Bars represent the standard errors of the hypocenters. The seismic region of intermediate-depth earthquakes is delimited by solid contours.

the catalog depth of $137 \mathrm{~km}$. The focal depth has been estimated by several methods. Oncescu (1989) found a focal depth of $129 \mathrm{~km}$, determined by using the $p P-P$ intervals as measured on the broadband records from GEOSCOPE. The depth obtained using the JHD technique is $131 \mathrm{~km}$. Monfret et al. (1990) studied the source of the event from very long period surface wave and body wave modeling GEOSCOPE and reported that the depth is approximately $140 \mathrm{~km}$. These results coincide well with our result.

The focal depth of the 1990 ( $M$ 6.9) earthquake was determined to be $84 \pm 1 \mathrm{~km}$ in this study, which is close to the catalog depth of $89 \mathrm{~km}$.

Almost all of the relocated aftershocks of the 1986 and 1990 earthquakes have well-determined locations situated inside the seismic region. On the contrary, it is very difficult to locate aftershocks for the 1940 and 1977 earthquakes and to define their aftershock areas accurately because few aftershocks and stations are available. Because there are so few aftershocks for these earthquakes, we also relocated and plotted a number of non-immediate aftershocks. If we compare the 1986 and 1990 earthquakes and their aftershock areas with the geometry of the seismic active volume, we can presume how the aftershock areas of the 1940 and 1977 earthquakes look like (Fig. 6(b)). Furthermore, each mainshock is situated at the NE edge of its aftershock area, which indicates the unilateral rupture toward SW.

We note that the horizontal size of the source area of the 1977 earthquake, as estimated by waveform analyses, extends about 50-60 km from the hypocenter towards the SW (Muller et al., 1978; Fuchs et al., 1979; Hartzell, 1979; Raker and Muller, 1982; Iosif et al., 1983). This estimation also coincides with the aftershock distribution determined by Fuchs et al. (1979) and our result. Oncescu and Bonjer (1997) found that the rupture of the 1940 earthquake propagated downwards and southwestwards, which is consistent with our result.

In order to compare location of mainshocks and aftershock areas, we combine Figs. 5(a)-(d) and make Fig. 6(b).

\section{Seismic Gap}

The aftershock areas of the four large earthquakes fill the seismic region between depths of 60 and $140 \mathrm{~km}$, while no large earthquake occurred at between depths of 140 and $160 \mathrm{~km}$. The $M 7$ earthquake that preceded the 1940 earthquake occurred in 1908 (M 7.1 by ROMPLUS). The depth of the 1908 earthquake reported by International Seismological Centre (2006) is the Gutenberg depth-150 kmwhile the ROMPLUS depth is $125 \mathrm{~km}$. According to the International Seismological Centre (2006), two depths have been reported for the 1940 earthquake: $96 \mathrm{~km}$ by ISS and $150 \mathrm{~km}$ by Gutenberg. Despite the unavoidable depth errors, we can assume that the 1908 earthquake occurred at depth of 140-160 km and that no (large) earthquakes have occurred at that depth since then up to the present (Fig. 6).

There are two noteworthy characteristics of the seismic gap identification. Firstly, only an area at the depth of 140$160 \mathrm{~km}$ in the seismic region remains unbroken by last three $M 7$ class earthquakes. Secondly, M 7 class earthquakes occur repeatedly at the same place. However, we cannot discuss this problem in detail because no data (accurate hypocenters) are available before 1940. Therefore, we focused only on the first point. The second problem will be studied in another paper.

There is a possibility that large earthquakes cannot occur in the bottom portion of the seismic region. However, since the seismicity appears to be homogeneous inside the seismic region, especially in the depth range of 120-160 km, it is natural to consider that large earthquakes can also occur in the bottom portion of the seismic region.

Assuming that the focal depth of the 1940 earthquake 
(a)
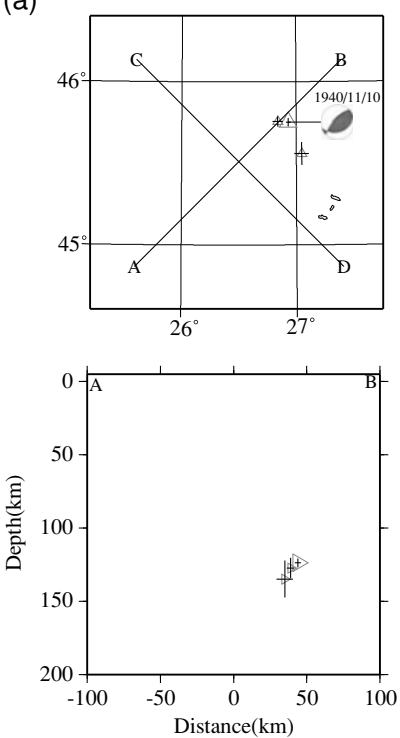

(c)

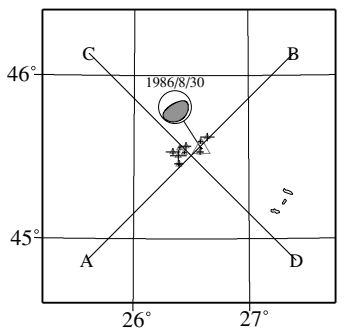

(b)
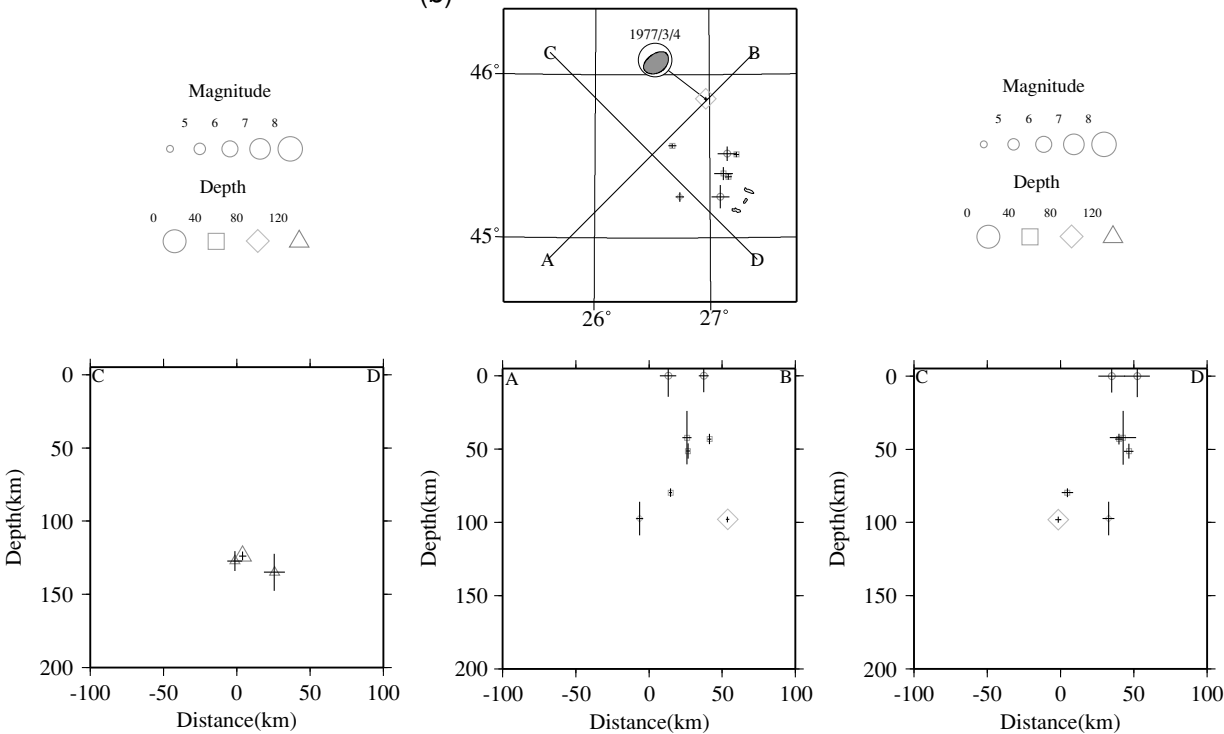

(d)
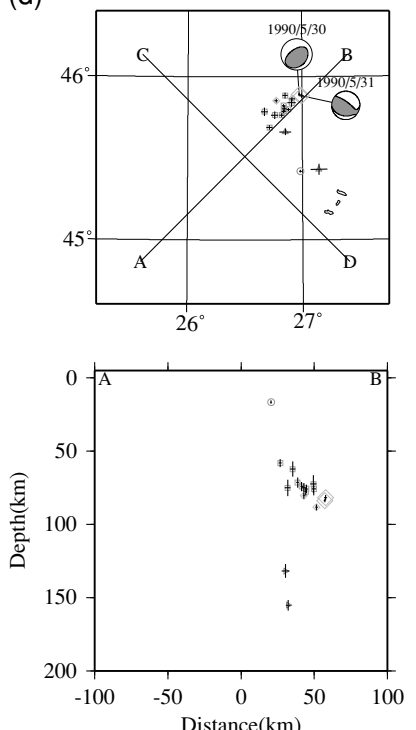

Magnitude

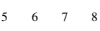

$\circ \bigcirc \bigcirc \bigcirc$

Depth

${ }^{40} \quad 80 \quad 120$

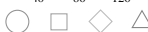

Distance $(\mathrm{km})$
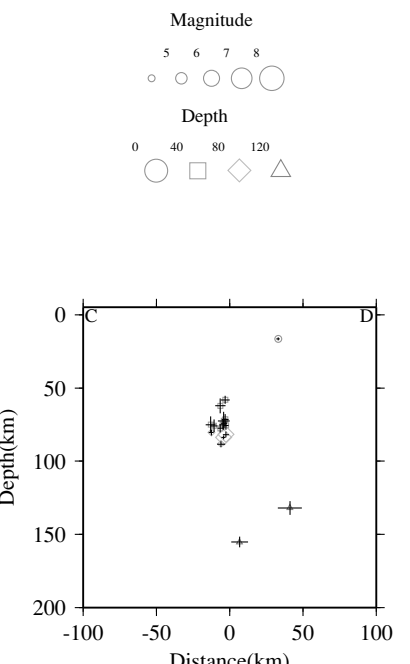

Fig. 5. Relocated hypocenters of major earthquakes and their aftershocks. Epicentral distribution and two vertical cross sections along the A-B and C-D directions are shown. (a) 1940 (M 7.7), (b) 1977 (M 7.5), (c) 1986 (M 7.2), (d) 1990 (M 6.9). Only earthquakes of which standard errors of focal depths and epicenters are less than $20 \mathrm{~km}$ and $0.1^{\circ}$, respectively are plotted. Bars represent the standard errors of the hypocenters. The fault plane solution of the 1940 earthquake by Oncescu and Bonjer (1997) and Centroid Moment Tensor (CMT) solutions of the 1977, 1986 and two 1990 earthquakes by Harvard University (Dziwonski et al., 1981, and later updates) are also shown.

was $150 \mathrm{~km}$, Oncescu and Bonjer (1997) suggested that the depth interval of $110-130 \mathrm{~km}$ has remained unbroken over the past 200 years and that they expect an $M 7.0$ 7.4 earthquake to occur there. They used depth phases to constrain the depth of the 1940 earthquake. Although the average of all stations indicated a depth of $133 \pm 27 \mathrm{~km}$, which agrees with our result $(124 \pm 3 \mathrm{~km})$, these researchers made a subsequent selection of stations, assuming that for some of them the emergent $P$-wave onset could not be properly detected. This selection let to an increase of the focal depth (down to a depth of $150 \pm 8 \mathrm{~km}$ ). However, the identification and readings of later phases might be very difficult and unreliable on the analog records available at that time. Our relocation of the 1940 earthquake indicates a focal depth of $124 \mathrm{~km}$, which leads to a totally different image: now the depth interval of $110-130 \mathrm{~km}$ corresponds to the source area of the 1940 earthquake and not at all to a present-day seismic gap. Therefore, the next Vrancea major shock is expected to occur in the deeper part of the active volume (in the 140- to $160-\mathrm{km}$ depth interval).

The seismic gap theory can be applied to shallow plate boundaries, where interplate earthquakes repeatedly occur along the plate boundaries. However, Vrancea intermediate-depth earthquakes are intraplate earthquakes that occur inside a subducting plate, and the plate is not parallel to their fault planes but to tensional $(T)$ axes (except for the 1986 earthquake, as shown in Fig. 6(b)). Although there is a significant difference in fault plane geometry between interplate and intraplate earthquakes, we can apply the seismic gap theory to intraplate earthquakes if we consider that the seismic energy is repeatedly released inside the plate instead of the plate showing repeated slipping (dis- 
(a)
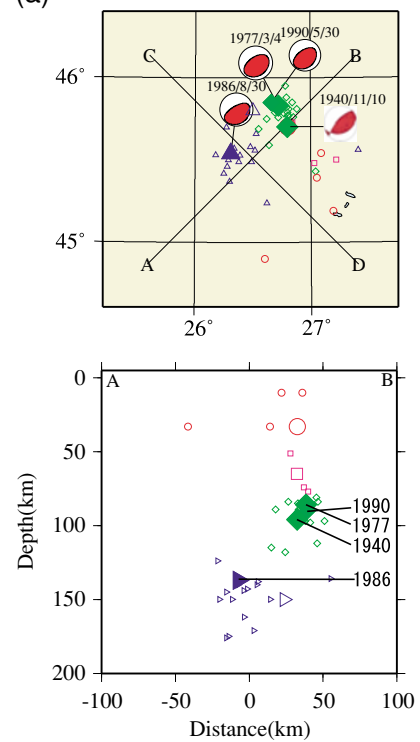

(b)
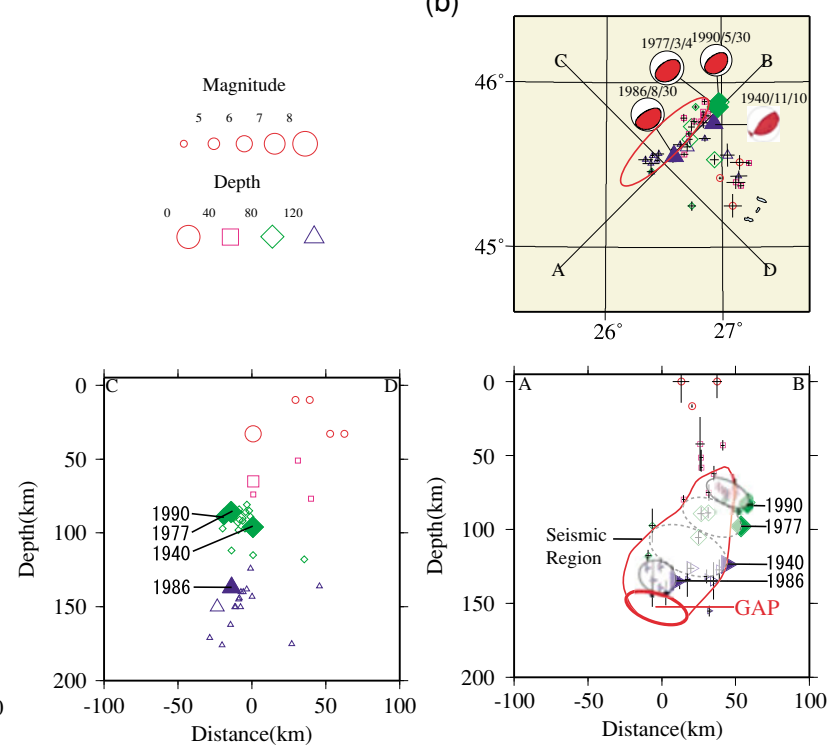

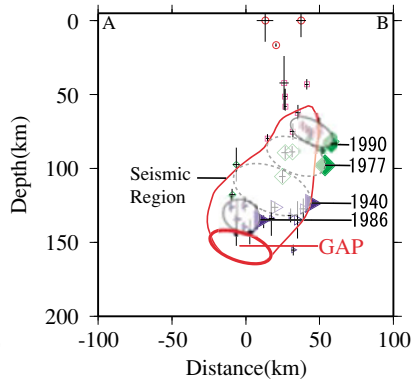

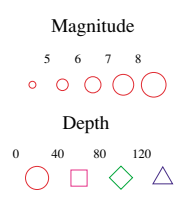

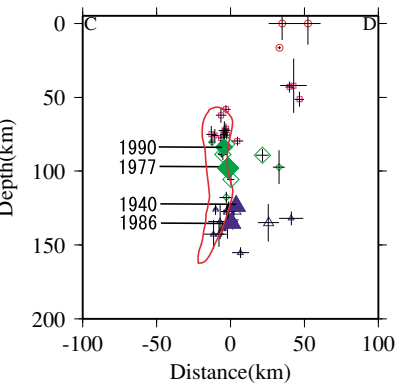

Fig. 6. Hypocenters of $M \geq 6$ earthquakes that occurred between 1934 and 1990 and aftershocks of the 1940, 1977, 1986 and 1990 main events. The hypocenters of four larger earthquakes and aftershocks of the 1986 and 1990 earthquakes are indicated by solid symbols. The fault plane solution of the 1940 earthquake by Oncescu and Bonjer (1997) and Centroid Moment Tensor (CMT) solutions of the 1977 , 1986 and 1990 earthquakes by Harvard University (Dziwonski et al., 1981, and later updates) are also shown. (a) Catalog hypocenters, (b) relocated hypocenters. The seismic region of intermediate-depth earthquakes defined in Fig. 4(b) is shown by solid contours. Two small solid and two dotted ellipses in the SW-NE cross section indicate the aftershock areas of the 1986 and 1990 earthquakes and the presumed aftershock areas of the 1940 and 1977 earthquakes, respectively. A large solid ellipse indicates a seismic gap where no large earthquakes have occurred since at least 1909.

placement) along the plate boundary.

According to the seismic gap hypothesis and to our analysis of Vrancea relocated events, we expect the next $M 7$ earthquake to have the following parameters: an approximate epicenter of $45.6^{\circ} \mathrm{N}, 26.6^{\circ} \mathrm{E}$ and a focal area located in the depth range of $140-160 \mathrm{~km}$; the expected rupture will be unilateral toward the SW and along a length of about $50 \mathrm{~km}$.

\section{Discussion}

The first and second datasets used in the combined simultaneous relocations share eight common stations. Epicentral distances from the center of the region $\left(45.7^{\circ} \mathrm{N}, 26.8^{\circ} \mathrm{E}\right)$ to all of these eight stations are less than 1.5 degrees. These eight stations recorded 11-33 earthquakes among the 47 earthquakes ultimately placed in the first dataset. In contrast, these eight stations observed more than 180 earthquakes among 502 earthquakes ultimately placed in the second dataset. Four of the eight stations recorded more than 400 events. Therefore, we suggest that our two datasets were effectively combined by common stations and earthquakes between the two datasets. This leads to reliable relative locations between the two datasets.

$S$-wave arrival times are believed to improve the location of hypocenters, because $S$ - $P$ times can constrain hypocentral distances. However, we did not use $S$-wave arrival times but only $P$-wave arrival times in this study because the reading accuracy of the $S$-wave arrival times is much worse than that of $P$-wave arrivals. In particular, accurate readings are necessary for the JHD method. If sufficient numbers of $P$ wave arrival times are available, the less accurate $S$-wave arrival times actually make the location worse. This is the case of the 1940 M 7.7 earthquake. According to ISS, 20 stations reported both $P$ - and $S$-wave arrival times for the 1940 earthquake. The average and the standard deviation of the travel time residuals for the $P$ - and $S$-wave arrival times are $-0.31 \pm 1.66 \mathrm{~s}$ and $0.89 \pm 16.45 \mathrm{~s}$, respectively. Even if we used only 15 stations in which $S$-wave travel time residuals are less than $10 \mathrm{~s}$, the average and the standard deviation of the $S$-wave travel time residuals are $2.64 \pm 4.66 \mathrm{~s}$. Therefore, the reading accuracy of $S$-wave arrival times is threefold worse than that of $P$-wave arrival times. Consequently, we decided to use only $P$-wave arrival times.

We were able to locate the 1940 earthquake quite accurately by the MJHD method, even though only one nearby station was available for this event. Let us show how its location improved. For the nearest 24 stations, of which epicentral distances are less than 20 degrees, the average and standard deviation of $P$ travel time residuals are $-0.55 \pm 1.88 \mathrm{~s}$ for the ISS location and $-0.11 \pm 0.87 \mathrm{~s}$ for the MJHD location. Furthermore, the root of the square sum of travel-time residuals are $9.41 \mathrm{~s}$ for ISS and $4.22 \mathrm{~s}$ for MJHD. These figures show an improvement for the 1940 earthquake location.

Purcaru (1974, 1979) and Enescu et al. (1974) predicted the 1977 earthquake and a next large earthquake occurrence approximately in 2005 based on regularities in the seismic activity over the past 1000 years, but they did not consider earthquake depth in their analysis - i.e. that earthquakes occur repeatedly at the same epicentral area. This neglected this aspect because the depth extent $(100 \mathrm{~km})$ is larger than the horizontal extent of the source region $(85 \times 20 \mathrm{~km})$ and the depth estimate was not enough accurate. The relocation method applied in this study allows the accurate determination of older earthquakes and their aftershock areas and the identification of the source region of each large earthquake. 
This is an essential step in predicting future earthquakes. The prediction based on accurate hypocenter locations, including focal depths, is common for interplate earthquakes in subduction zones, such as Kurile and Japan trenches (e.g. Fedotov, 1965; Sykes, 1971), but this is the first time it has been applied to an intermediate-depth earthquake. Since an $M 7$ earthquake occurs every 20-30 years and causes seismic damage in Romania and neighboring countries, the accuracy of the prediction urgently needs improvement. Note also that the spatial distribution of damage in the case of the Vrancea earthquakes is strongly dependent not only on size, but also on depth and rupture propagation mode. Therefore, it is worthwhile including these parameters in any prediction assessment. Our results provide seismological backgrounds for the regularity of Vrancea earthquakes and provide important and new tools to better constrain the parameters of the next expected strong earthquake.

\section{Conclusions}

A long-term earthquake prediction is based on the regularity of earthquake occurrences and a seismic gap theory. Based on reported history, an $M 7$ intermediate-depth earthquake occurs in the Vrancea region of Romania on average every 20-30 years. Therefore, a next large earthquake is expected to occur soon. To predict the next $M 7$ earthquake, we need to accurately determine the hypocenters of past earthquakes. To this end, we relocated large intermediatedepth earthquakes that have occurred in Vrancea since 1934. Combining these and recent (from January 1996 to November 2003) smaller earthquakes reported by the Romanian local network, we relocated all of them simultaneously using a MJHD method (Hurukawa and Imoto, 1992; Hurukawa, 1995). The size of the active seismic region was estimated on the basis of recent small earthquakes data as follows: $85 \mathrm{~km}$ length along the NE-SW direction, $20 \mathrm{~km}$ width and 60- to $160-\mathrm{km}$ depth range. We found that the 1940 (M 7.7), 1977 (M 7.5) and 1990 (M 6.9) major earthquakes were located near the NE edge of the seismic region, although the 1986 (M 7.2) was located inside the seismic region. Focal depths of the 1940, 1977, 1986 and 1990 earthquakes were 124, 98, 135 and $84 \mathrm{~km}$, respectively. Based on aftershock distribution of these earthquakes, we conclude that their source areas are located inside the above defined seismic region in the depth range of $60-140 \mathrm{~km}$. The only area at a depth of 140-160 km remains unbroken at present so that we expect that the next $M 7$ earthquake will occur in this area at the beginning of this century.

Acknowledgments. We thank Dr. M. Imoto for his useful comments that resulted in an improvement of this study. We also thank Prof. C. Frohlich and an anonymous reviewer for their constructive comments.

\section{References}

Douglas, A., Joint epicenter determination, Nature, 215, 47-48, 1967.

Dziwonski, A. M., T.-A. Chou, and J. Woodhouse, Determination of earthquake source parameters from waveform data for studies of global and regional seismicity, J. Geophys. Res., 86, 2825-2852, 1981.

Enescu, D. and B. D. Enescu, Focal mechanism, global geophysical phenomena and Vrancea (Romania) earthquake prediction, Rev. Roum.
Geophys., 40, 11-31, 1996.

Enescu, D. and B. D. Enescu, Possible cause-effect relationships between Vrancea (Romania) earthquakes and some global geophysical phenomena, Natural Hazards, 19, 233, 1999.

Enescu, D., V. Marza, and I. Zamarca, Contributions to the statistical prediction of Vrancea earthquakes, Rev. Roum. Geophys., 18, 67, 1974.

Fedotov, S. A., Regularities of the distribution of strong earthquakes in Kamchatka, the Kurile Islands and northeastern Japan, Acad. Sci. USSR Trudy Inst. Physics Earth, 36, 1965.

Freedman, H. W., A statistical discussion of P residuals from explosions, Part 2, Bull. Seismol. Soc. Am., 57, 545-561, 1967.

Frohlich, C., Deep earthquakes, Cambridge Uni. Press, 2006.

Fuchs, K., K.-P. Bonjer, G. Bock, I. Cornea, C. Radu, D. Enescu, D. Jianu, A. Nourescu, G. Merkler, T. Moldoveanu, and G. Tudorache, The Romanian earthquake of March 4, 1977, II. Aftershocks and migration of seismic activity, Tectonophysics, 53, 225-247, 1979.

Hartzell, S., Analysis of the Bucharest strong ground motion record for the March 4, 1977 Romanian earthquake, Bull. Seismol. Soc. Am., 69, 513-530, 1979.

Headquarters for Earthquake Research Promotion, http://www.jishin.go. jp/main/index-e.html, 2007.

Hurukawa, N., Quick aftershock relocation of the 1994 Shikotan earthquake and its fault planes, Geophys. Res. Lett., 22, 3159-3162, 1995.

Hurukawa, N. and M. Imoto, Subducting oceanic crusts of the Philippine Sea and Pacific plates and weak-zone-normal compression in the Kanto district, Japan, Geophys. J. Int., 109, 639-652, 1992.

Imoto, M. and N. Hurukawa, Assessing potential seismic activity in Vrancea, Romania, using a stress-release model, Earth Planets Space, 58, 1511-1514, 2006.

International Seismological Centre, On-line Bulletin, http://www. isc.ac.uk/Bull, Internatl. Seis. Cent., Thatcham, United Kingdom, 2006.

Iosif, T., M. C. Oncescu, and S. Iosif, March 4, 1977 Vrancea earthquake, spatial distribution of events and temporal evolution of focal mechanism, Bull. Int. Inst. Seismol. Earthq. Eng., 20, 1-18, 1983.

Monfret, T., A. Deschamps, and B. Romanowicz, The Romanian earthquake of August 30, 1986: A study based on GEOSCOPE very longperiod and broadband data, Pageoph, 133, 367-379. 1990.

Muller, G., K.-P. Bonjer, H. Stockl, and D. Enescu, The Romanian earthquake of March 4, 1982, I. Rupture process inferred from fault-plane solution and multiple-event analysis, J. Geophys., 44, 203-218, 1978.

Oncescu, M. C., Investigation of a high stress drop earthquake on August 30, 1986 in the Vrancea region, Tectonophysics, 163, 35-43, 1989.

Oncescu, M. C. and K. P. Bonjer, A note on the depth recurrence and strain release of large Vrancea earthquakes, Tectonophysics, 272, 291-302, 1997.

Oncescu, M., V. I. Marza, M. Rizescu, and M. Popa, The Romanian earthquake catalogue between 1984-1997, in Vrancea Earthquakes: Tectonics, Hazard Risk Mitigation, edited by F. Wenzel et al., 43-47, 1999.

Purcaru, G., Quasi- and supercyclicity of earthquakes and time-magnitude gaps in earthquake prediction, Tech. Rep., NORSAR, Sci. Rep., No. 673/74, 53-55, 1974.

Purcaru, G., The Vrancea, Romania, earthquake of March 4, 1977-A quite successful prediction, Phys. Earth Planet. Inter., 18, 274-287, 1979.

Radulian, M. and C. I. Trifu, Would it have been possible to predict the August 30, 1986 Vrancea earthquake?, Bull. Seismol. Soc. Am., 81, 2498-2503, 1991.

Rakers, E. and G. Muller, The Romanian earthquake of March 4, 1977, III. Improved Focal Model and Moment Determination, J. Geophys., 50, 143-150, 1982.

Sperner, B., D. Ioane, and R. J. Lillie, Slab behaviour and is surface expression: new insights from gravity modeling in the SE-Carpathians, Tectonophysics, 382, 51-84, 2004.

Sykes, L. R., Aftershock zones of great earthquakes, seismicity gaps, and earthquake prediction for Alaska and the Aleutians, J. Geophys. Res., 76, 8021, 1971 .

Wortel, M. J. R. and W. Spakman, Subduction and slab detachment in the Mediterranean-Carpathian region, Science, 290, 1910-1917, 2000.

N. Hurukawa (e-mail: hurukawa@kenken.go.jp), M. Popa, and M. Radulian 